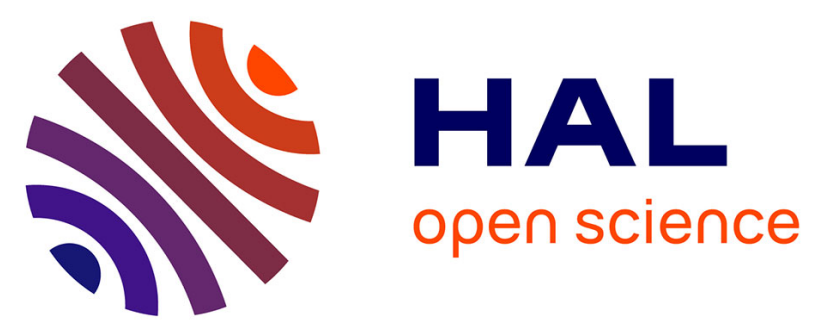

\title{
Nonlinear acoustic resonances to probe a threaded interface
}

\author{
Jacques Rivière, Guillaume Renaud, Sylvain Haupert, Maryline Talmant, \\ Pascal Laugier, Paul A. Johnson
}

\section{To cite this version:}

Jacques Rivière, Guillaume Renaud, Sylvain Haupert, Maryline Talmant, Pascal Laugier, et al.. Nonlinear acoustic resonances to probe a threaded interface. Journal of Applied Physics, 2010, 107 (12), pp.124901. 10.1063/1.3443578 . hal-01397225

\section{HAL Id: hal-01397225 \\ https://hal.sorbonne-universite.fr/hal-01397225}

Submitted on 15 Nov 2016

HAL is a multi-disciplinary open access archive for the deposit and dissemination of scientific research documents, whether they are published or not. The documents may come from teaching and research institutions in France or abroad, or from public or private research centers.
L'archive ouverte pluridisciplinaire HAL, est destinée au dépôt et à la diffusion de documents scientifiques de niveau recherche, publiés ou non, émanant des établissements d'enseignement et de recherche français ou étrangers, des laboratoires publics ou privés. 


\title{
Nonlinear acoustic resonances to probe a threaded interface
}

\author{
Jacques Rivière, ${ }^{1, a)}$ Guillaume Renaud, ${ }^{1}$ Sylvain Haupert, ${ }^{1}$ Maryline Talmant, ${ }^{1}$ \\ Pascal Laugier, ${ }^{1}$ and Paul A. Johnson, $\left.{ }^{2}, \mathrm{~b}\right)$ \\ ${ }^{1}$ Laboratoire d'Imagerie Paramétrique, CNRS UMR 7623, UPMC Univ Paris 06, F-75006 Paris, France \\ ${ }^{2}$ Los Alamos National Laboratory, New Mexico, USA
}

(Received 8 January 2010; accepted 5 May 2010; published online 16 June 2010)

\begin{abstract}
We evaluate the sensitivity of multimodal nonlinear resonance spectroscopy to torque changes in a threaded interface. Our system is comprised of a bolt progressively tightened in an aluminum plate. Different modes of the system are studied in the range $1-25 \mathrm{kHz}$, which correspond primarily to bending modes of the plate. Nonlinear parameters expressing the importance of resonance frequency and damping variations are extracted and compared to linear ones. The influence of each mode shape on the sensitivity of nonlinear parameters is discussed. Results suggest that a multimodal measurement is an appropriate and sensitive method for monitoring bolt tightening. Further, we show that the nonlinear components provide new information regarding the interface, which can be linked to different friction theories. This work has import to study of friction and to nondestructive evaluation of interfaces for widespread application and basic research. (C) 2010 American Institute of Physics. [doi:10.1063/1.3443578]
\end{abstract}

\section{INTRODUCTION}

Our work is aimed at exploring the application of elastic nonlinear methods to probe the physics of interfaces, and to study medical and industrial applications. In this study we focus in a problem that appears simple, the tightening of a screw or bolt in a metal plate-but turns out to be highly complex. Widely used in many industrial applications, bolted structures have been a research domain for many years, from the conception of these structures to development of quality control devices of tightening. Ultrasonic methods occupy an important position in quality control and monitoring. Several publications appeared in the 1970s applying the variation in the first compressional resonance mode of the screw to determine the tightening forces on it, either in the time domain or in the frequency domain. ${ }^{1-4}$ In the time domain, a pulse echo system provides the means to measure the time of flight of a longitudinal wave within a screw. Variation in wave speed gives information on the tightening forces (acoustoelastic effect). ${ }^{2,4}$

Recently a real-time tightening control was developed by Nassar and Veeram ${ }^{5}$ based on the time domain measurement. Similarly, Chaki et al. ${ }^{6}$ developed a system combining longitudinal and transversal waves in industrial applications.

Furthermore, many studies have been performed to detect loosening of rivets, widely used in aeronautics. For example, the combination of thermography and ultrasound techniques allows one to detect flawed rivets. ${ }^{7,8}$ The structure is excited by ultrasound, which causes heating of flawed rivets by dissipation and thermography is used to detect heated regions. More generally, methods using Eddy current, ${ }^{9-11}$ $\mathrm{x}$-radiography, ${ }^{12,13}$ or magneto-optic interactions ${ }^{14,15}$ are also either in progress or already employed for riveted structures.

In the medical domain, Meredith et al. ${ }^{16}$ developed the

\footnotetext{
${ }^{a)}$ Electronic mail: jacques.riviere@upmc.fr.

${ }^{b)}$ Electronic mail: paj@lanl.gov.
}

resonance frequency analysis method in 1996 to assess the stability of a dental implant. A L-shape sensor is fixed to the dental implant after surgery to monitor bone healing. Indeed, the first bending resonance of the "sensor-implant" system is sensitive to stress exerced by bone surrounding the implant. Similarly, the Periotest $\bigcirc$ device developed by Dhoedt et al. ${ }^{17}$ in 1985 consists of damping measurements of the implant/bone system by means of a calibrated impact.

Little work has been done applying nonlinear acoustics on this subject. Very recent publications ${ }^{18,19}$ reported the sum-frequency level $\left(f_{1}+f_{2}\right)$ created by exciting bolted joints with two sinusoidal waves $\left(f_{1}\right.$ and $\left.f_{2}\right)$, for different torque levels. More generally, nonlinear acoustics offers sensitive techniques to detect an isolated and localized microcrack, ${ }^{20}$ as well as to evaluate the global quantity of microdamage in materials such as rock, ${ }^{21,22}$ nickel, ${ }^{23}$ concrete, ${ }^{24-26}$ wood, ${ }^{27}$ bone, ${ }^{28,29}$ etc. These techniques are primarily based on harmonic generation, ${ }^{30-32}$ frequency mixing, ${ }^{33-35}$ acoustoelasticity, ${ }^{36,37}$ or shift in the resonance frequency. ${ }^{26,28,38,39}$ The latter provides the means to extract nonlinear elastic and dissipative parameters, associated to changes in the resonance frequency and damping with level of excitation, respectively.

The aim of this study is first to evaluate the sensitivity of nonlinear acoustic resonance spectroscopy to torque changes, in a system composed of a screw tightened in a plate. From an application point of view and in comparison with traditional linear measurements, we expect these nonlinear measurements to bring some complementary information and/or better sensitivity. Second, the interpretation of these results will lead to emphasize the physics of some potential interesting models, that could explain the physical process at the interface.

\section{THEORY}

In the framework of linear elasticity, stress and strain are linearly related by a constant elastic modulus. If nonlinearity 
has to be considered, Landau theory ${ }^{40}$ allows to describe "classical" materials, where nonlinearity arises from atomic scale (nanoscopic scale). In the case of more complex materials, either heterogeneous, cracked, or granular (mesoscopic scales), and for strain above roughly $10^{-6}, 41,42$ Landau theory is no longer valid. ${ }^{43,44}$ Indeed, some typical behaviors appear in this case: an hysteresis with cusps is present in the stressstrain response, odd harmonics are favored, resonance frequency exhibits a linear shift with level of excitation, ${ }^{38}$ and a slow dynamic phenomenon appears. ${ }^{45,46}$ The physical origins of these phenomena, which are still not completely understood, comes from a rearrangement of grains (dislocations, rupture, recovery bonds) which can be modeled as friction and/or clapping, together with a thermoelastic effect. ${ }^{47}$ The "hysteretic" regime (except slow dynamics effect) of these materials has been modeled phenomenologically by Guyer and $\mathrm{McCall},{ }^{48,49}$ using the Preisach-Mayergoyz space (PM space). We choose the description of this model, as it is one of the most simple and universal to introduce nonlinear elasticity in diverse materials/systems. This choice will give us a baseline for our experiment. In the discussion, different physics-based models and physical origins will be described. The PM space formalism decomposes materials into hysteretic mesoscopic units, which alternatively open and close at different pressure values. Equation (1) describing the nonlinear elastic modulus $K$ in a one-dimensional case can be derived in the case of small acoustic strain, where a nonlinear nonclassical (or hysteretic) parameter $\alpha$ has been added to the nonlinear classical development of Landau (parameters $\beta$ and $\delta$ of first and second order representing the quadratic and cubic nonlinearities, respectively)

$$
K(\epsilon, \dot{\epsilon})=K_{0}\left\{1-\beta \epsilon-\delta \epsilon^{2}-\ldots-\alpha[\Delta \epsilon+\operatorname{sign}(\dot{\epsilon}) \epsilon]\right\},
$$

where $K_{0}, \epsilon, \dot{\epsilon}$, and $\Delta \epsilon$ are the linear modulus, the strain, the time derivative of strain, and the maximum strain excursion over a wave cycle, respectively. As the interface studied (threads) is at a mesoscopic scale, we expect to obtain a nonlinear hysteretic behavior, where the parameter $\alpha$ dominates over $\delta$. In this case, a first order approximation gives the Eqs. (2) and (3). ${ }^{50}$ Equation (2) leads to the nonlinear elastic parameter $\alpha_{f}$ (shift in the resonance frequency), whereas, Eq. (3) leads to the nonlinear dissipative parameter $\alpha_{\xi}$ (damping variation)

$$
\begin{aligned}
& \frac{f-f_{0}}{f_{0}}=\alpha_{f} \epsilon, \\
& \frac{1}{Q}-\frac{1}{Q_{0}}=2 \xi-2 \xi_{0}=2 \xi_{0}\left(\frac{V \epsilon_{0}}{V_{0} \epsilon}-1\right)=\alpha_{\xi} \epsilon,
\end{aligned}
$$

where $f, \xi, V$, and $Q$ are the resonance frequency, the modal damping ratio, the voltage amplitude of excitation, and the quality factor, respectively. The subscript " 0 " refers to the value obtained with the lowest amplitude of excitation (considered as a linear regime value). $\alpha_{f}$ and $\alpha_{\xi}$ are both proportional to the parameter $\alpha$ of Eq. (1). Equation (3) makes the assumption that strain is inversely proportional to the modal damping ratio. ${ }^{50}$ This allows one to extract $\alpha_{\xi}$ without mea-

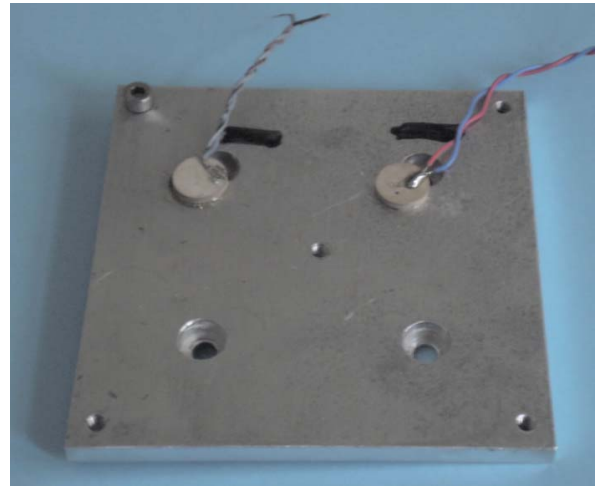

FIG. 1. (Color online) Aluminum plate used in the experiment. A M4-screw is tightened in the upper left. Two piezoelectric sensors are bonded to the plate.

suring $\xi$, an arduous problem in the frequency domain with a nonlinear regime.

\section{MATERIAL AND METHODS}

\section{A. Material}

Our system (Fig. 1) is composed of a steel screw (M4, $16 \mathrm{~mm}$ long) tightened at different torques in the corner of an aluminum plate $\left(10 \times 10 \mathrm{~cm}^{2}\right)$, using a screwdriver. The torque range chosen is $15-150 \mathrm{~N} \mathrm{~cm}$. Below $15 \mathrm{~N} \mathrm{~cm}$, the screw can be loosened by hand. We tighten until $150 \mathrm{~N} \mathrm{~cm}$, a value close to the maximum permissible value for this screw diameter ( $250 \mathrm{~N} \mathrm{~cm}$ typically). The system is suspended by a string to obtain free boundary conditions. Two piezoelectric sensors (PZT-5A, $12 \mathrm{~mm}$ diameter, $2 \mathrm{~mm}$ thick) are bonded on the plate with glue, one is used as an emitter, the other as a receiver. The excitation is provided by a 14-bit waveform generator (Spectrum M2i6012) fed into a Tegam 2350 amplifier. The acquisition is performed applying a 14-bit Spectrum M2i4022 card.

\section{B. Identification by finite element modeling (FEM)}

The frequency range studied is $1-25 \mathrm{kHz}$. Above 25 $\mathrm{kHz}$, the density of modes is so great that they overlap and it becomes difficult to perform the measurement on an isolated mode. These modes are identified with a finite element model, using an eigenmode study. In this model, all geometrical characteristics are respected, except thread which is not represented. We model the contact plate/screw and plate/ sensors as perfect (same displacement). Elastic characteristics included in the model for the aluminum plate, the steel screw and the PZT sensors are $70 \mathrm{GPa}, 900 \mathrm{GPa}$ and $70 \mathrm{GPa}$, respectively, for the Young modulus E, $2700 \mathrm{~kg} / \mathrm{m}^{3}$, $7850 \mathrm{~kg} / \mathrm{m}^{3}$, and $7750 \mathrm{~kg} / \mathrm{m}^{3}$, respectively, for the density $\rho$. These values are typical from the literature and have not been matched to fit experimental resonance frequencies. The model does not include dissipative charateristics. Then, numerically obtained eigenfrequencies are compared to experimental ones, measured for the maximum torque $(150 \mathrm{~N} \mathrm{~cm}$ in our case). Eigenmodes present in the range $1-25 \mathrm{kHz}$ mainly correspond to bending modes of the plate (Fig. 3). These bending modes become more and more complex when 
TABLE I. Comparison between experiment $\left(f_{\text {exp }}\right)$ and finite element modeling $\left(f_{\text {mod }}\right)$. The quality factor $Q_{\text {exp }}$ is also given as information. All modes are identified except two (nos. 17 and 22) because of model's lacunae (cf. text). Note also that two in-plane modes are obtained by FEM but not excited in the configuration of the experiment (mode nos. 16 and 19).

\begin{tabular}{|c|c|c|c|c|c|}
\hline No. & $\begin{array}{l}f_{\exp } \\
(\mathrm{Hz})\end{array}$ & $\begin{array}{l}f_{\text {mod }} \\
(\mathrm{Hz})\end{array}$ & $\begin{array}{c}\left|f_{\text {mod }}-f_{\text {exp }}\right| \\
(\mathrm{Hz})\end{array}$ & 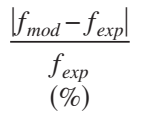 & $\begin{array}{c}Q_{\text {exp }} \\
(.)\end{array}$ \\
\hline 1 & 1846 & 1852 & 6 & 0.3 & 600 \\
\hline 2 & 3447 & 3421 & 26 & 0.8 & 280 \\
\hline 3 & 4665 & 4707 & 42 & 0.9 & 380 \\
\hline 4 & 4832 & 4869 & 37 & 0.8 & 140 \\
\hline 5 & 8140 & 8202 & 62 & 0.8 & 230 \\
\hline 6 & 8373 & 8375 & 2 & 0.0 & 200 \\
\hline 7 & 8567 & 8682 & 115 & 1.3 & 130 \\
\hline 8 & 9369 & 9529 & 160 & 1.7 & 300 \\
\hline 9 & 10330 & 10322 & 8 & 0.1 & 180 \\
\hline 10 & 13800 & 13958 & 158 & 1.1 & 140 \\
\hline 11 & 14010 & 14217 & 207 & 1.5 & 410 \\
\hline 12 & 15600 & 15850 & 250 & 1.6 & 300 \\
\hline 13 & 16040 & 16137 & 97 & 0.6 & 95 \\
\hline 14 & 17300 & 17499 & 199 & 1.1 & 320 \\
\hline 15 & 17450 & 17752 & 302 & 1.7 & 425 \\
\hline 16 & Not excited & 18402 & & & Not excited \\
\hline 17 & 19120 & Not detected & & & 90 \\
\hline 18 & 19380 & 19570 & 190 & 1.0 & 500 \\
\hline 19 & Not excited & 20319 & & & Not excited \\
\hline 20 & 20790 & 20880 & 90 & 0.4 & 380 \\
\hline 21 & 21460 & 21459 & 1 & 0.0 & 290 \\
\hline 22 & 23800 & Not detected & & & 100 \\
\hline
\end{tabular}

frequency increases. Mode nos. 16 and 19 correspond to modes whose displacement field is in the plane of the plate. These two modes are not present experimentally, as excitation favors out of plane modes. In Table I, we note that identification by FEM is efficient, regarding absolute and relative differences between experiment (Fig. 2) and modeling. However, two modes present experimentally at 19.1 and $23.8 \mathrm{kHz}$ are not identified in the modeling (mode nos. 17 and 22 in Table I). This poor identification can be explained by the fact that the thread is not modeled at the interface screw/plate.

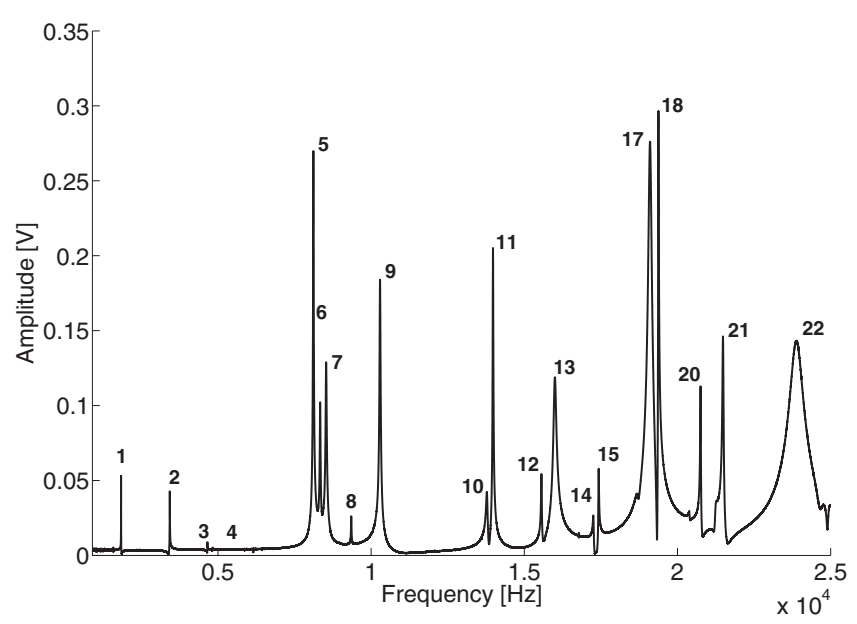

FIG. 2. Spectrum at $150 \mathrm{~N} \mathrm{~cm}$ in the range $1-25 \mathrm{kHz}$. Each number corresponds to a mode in Fig. 3 and Tables I and II.

\section{Measurement}

Each mode with linear resonance frequency $f_{0}$ is excited by a $1 \mathrm{~s}$ long linear frequency sweep, whose starting and stopping frequencies correspond to $f_{0} \pm 5 \%$. The frequency sweep is then repeated for 30 increasing amplitudes of excitation. The linear parameters $f_{0}$ and $\xi_{0}$ are measured by fitting a lorentzian ${ }^{50}$ to the resonance curve obtained for the lowest amplitude (considered as linear elastic). Resonance curves at higher amplitudes are fitted by a polynomial interpolation, allowing one to extract the resonance frequency $f$ and the corresponding amplitude. Finally, nonlinear elastic and dissipative parameters $\alpha_{f}$ and $\alpha_{\xi}$ are extracted for each mode, according to Eqs. (2) and (3). This procedure is then repeated for increasing torques.

Experiments are performed in a temperature controlled room $\left(25 \pm 1{ }^{\circ} \mathrm{C}\right)$. The duration time of $1 \mathrm{~s}$ for the frequency sweep has been selected as a compromise between the possible heating of the system and achieving a steady-state at each frequency during the sweep. The steady-state is reached at each frequency.

A waiting time between each excitation is needed to limit slow dynamics phenomenon from fast dynamics measurement. This waiting time was evaluated at the lowest torque (the case where nonlinearity is the highest). The resonance frequency of each mode is first measured with the weakest amplitude of excitation. Then, the system is excited with a $1 \mathrm{~s}$ long excitation at the highest amplitude used in the measurement. Just after, the resonance frequency is mea- 


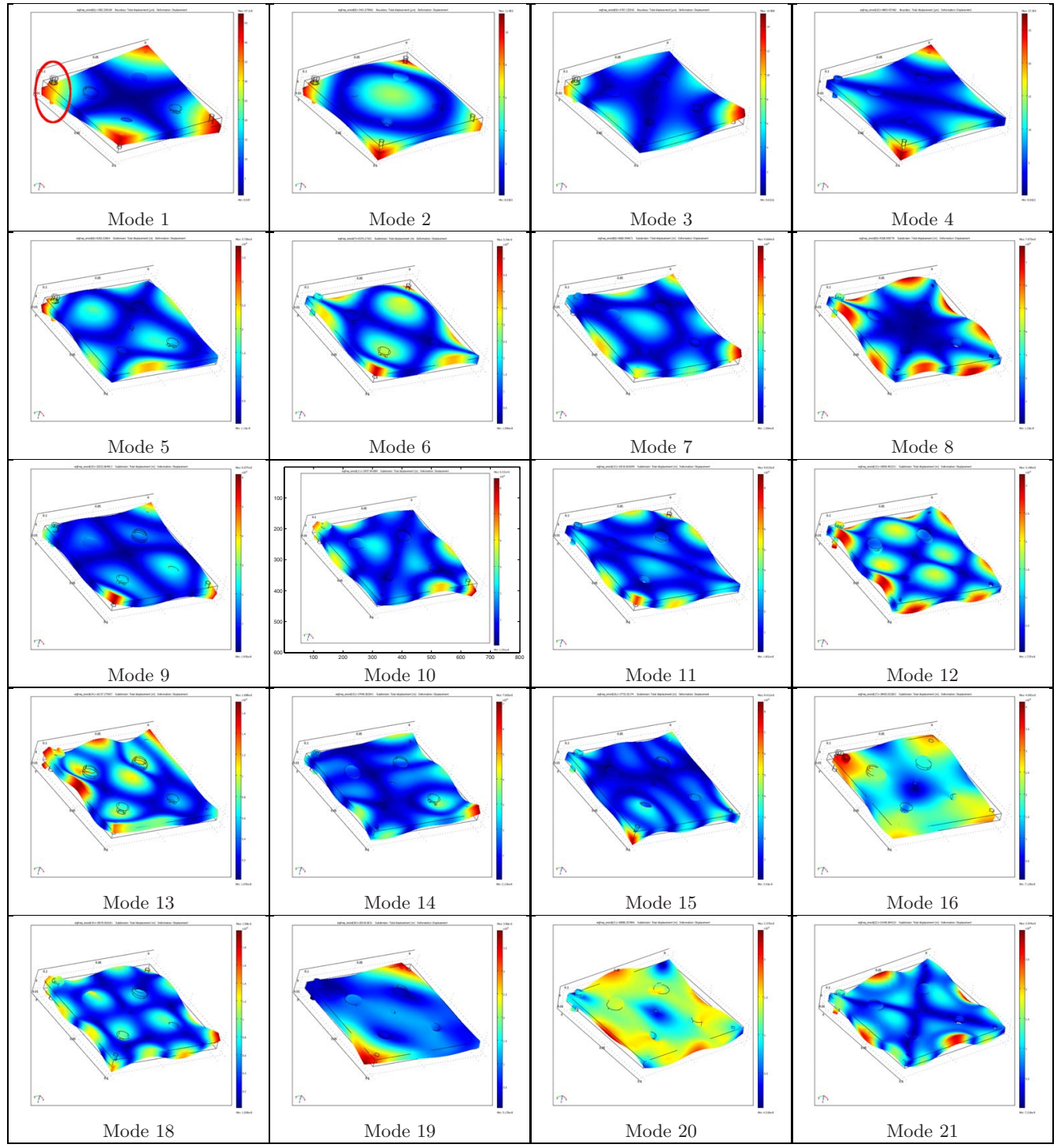

FIG. 3. (Color online) Eigenmodes obtained by finite element modeling. The position of the screw is shown by the circle for mode 1 . The scale indicates the displacement field: dark zones (or blue on color version) represent a zero displacement (or a maximum strain), and white zones (red zones on color version) represent a maximum displacement (or a zero strain). Corresponding frequencies are shown in Table I. Note that these modes mainly correspond to bending modes of the plate except modes nos. 16 and 19, which correspond to in-plane modes. Note also the absence of mode nos. 17 and 22, only present in the experiment.

sured again with the weakest amplitude. Therefore, it appears that less than $5 \mathrm{~s}$ are needed for the system to recover its original resonance frequency. We make the assumption that this characteristic time is the worst case (longest duration slow dynamics) and therefore a $10 \mathrm{~s}$ rest time is applied between each excitation.

\section{RESULTS}

Modes in the range 1-10 kHz (nos. 1-9) exhibit weak nonlinearity and little sensitivity to torque change. Most of modes in the range $10-25 \mathrm{kHz}$ exhibit higher nonlinearities at low torques. As an example, Fig. 4 shows typical behavior of mode no. 11 for 30 amplitudes, and seven torques from 15 to $150 \mathrm{~N} \mathrm{~cm}$. In this figure, we see qualitatively that the higher the torque, the higher the resonance frequency. Moreover, increasing torque leads to higher amplitudes and lower damping. Finally, the frequency shift decreases with applied torque. Indeed, as a first approximation, if we consider the most elementary vibrational system (generally termed massspring system), with a mass $m$ and a stiffness $k$, the resonance frequency of this system will be $f=(1 / 2 \pi) \sqrt{k / m}$. In

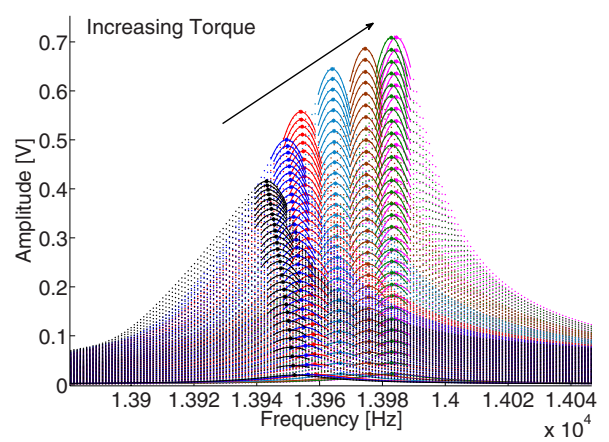

FIG. 4. (Color online) Mode No. 11 for 30 increasing amplitudes of excitation and seven torques from 15 to $150 \mathrm{~N} \mathrm{~cm}$. 


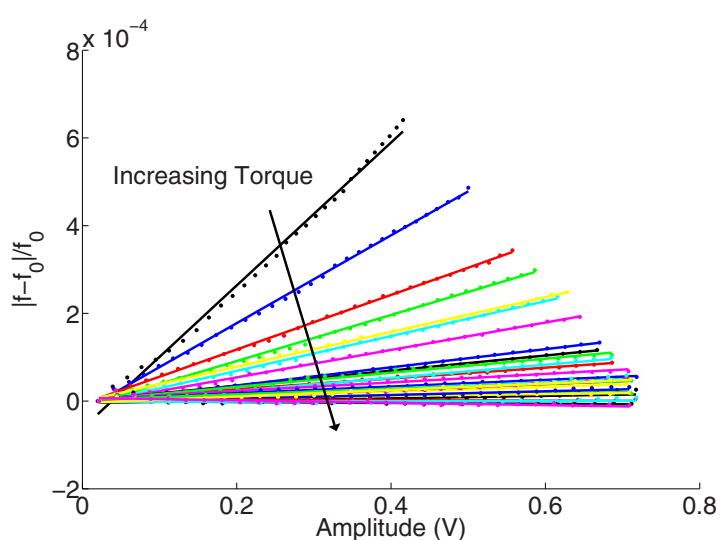

(a)

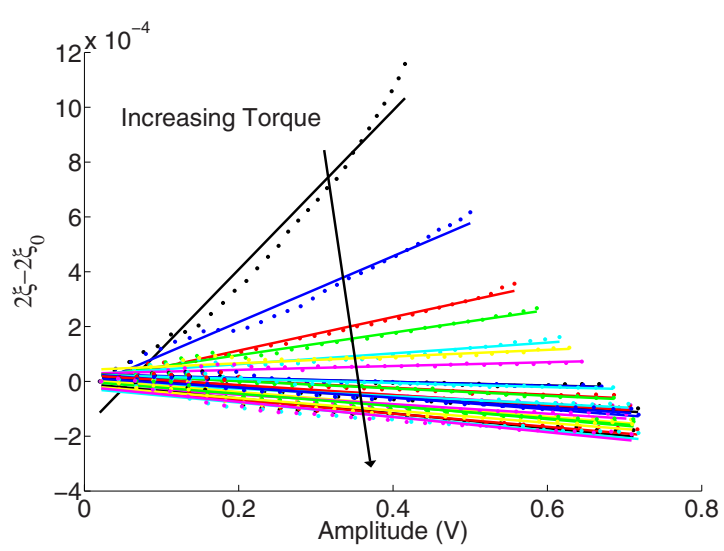

(b)

FIG. 5. (Color online) (a) Relative frequency shift $\left|f-f_{0}\right| / f_{0}$ of mode no. 11 vs voltage amplitude of detector (proportional to strain) for 28 increasing torques. Each curve is linearly fitted and the slope obtained corresponds to the parameter $\mathrm{C} \alpha_{f}$ with $\mathrm{C}$ a constant. (b) Damping variation $2 \xi-2 \xi_{0}$ of mode no. 11 vs voltage amplitude of detector (proportional to strain) for 28 increasing torques. Each curve is linearly fitted and the slope obtained corresponds to the parameter $\mathrm{C} \alpha_{\xi}$ with $\mathrm{C}$ a constant.

this system, $f$ is proportional to $\sqrt{k}$ and that is what we observe when increasing torque: stiffness increases for a same mass. Likewise, the contact screw/plate is more and more stressed when increasing torque. Thus, linear dissipation and elastic nonlinearity are present for low torques, as observed in Fig. 4, where linear dissipation induces "broader" modes and lower amplitudes and elastic nonlinearity induces higher frequency shift with drive amplitude. Quantitatively, these phenomena are represented from Figs. 5-9. Figure 5, the relative frequency shift $\left|f-f_{0}\right| / f_{0}$ and damping variation $2 \xi$ $-2 \xi_{0}$ are plotted versus voltage amplitude received by the detector sensor. In this figure, each curve is linearly fitted and the slope of each fit corresponds to $\mathrm{C} \alpha_{f}$ and $\mathrm{C} \alpha_{\xi}$, with $\mathrm{C}$ a constant (the amplitude in volts is proportional to strain). This slope decreases dramatically when torque increases, meaning that the system tends toward a linear regime.

In Figs. 6 and 7, we observe the behavior of nonlinear elastic and dissipative parameters, respectively, for four modes. These parameters decrease at low torques and then become independent of torque level. We can also note that mode no. 11 is present in the spectrum over the entire torque range, while modes 20,21 , and 22 appear at torques about 35 $\mathrm{N} \mathrm{cm}, 24 \mathrm{~N} \mathrm{~cm}$, and $35 \mathrm{~N} \mathrm{~cm}$, respectively. These modes

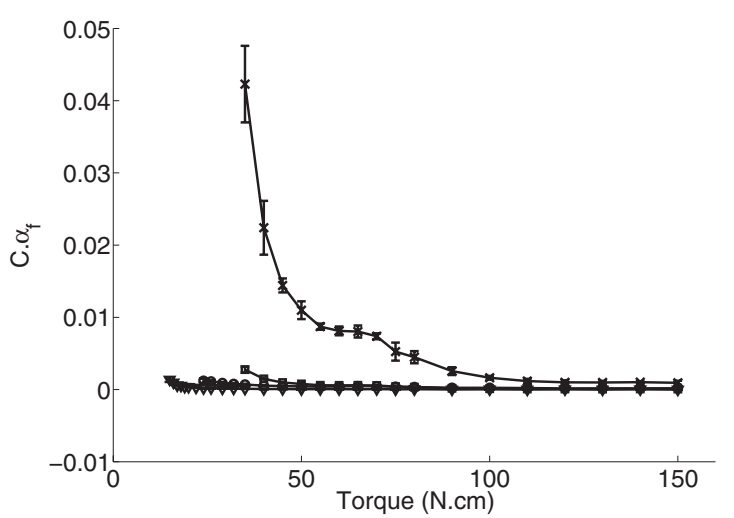

(a)

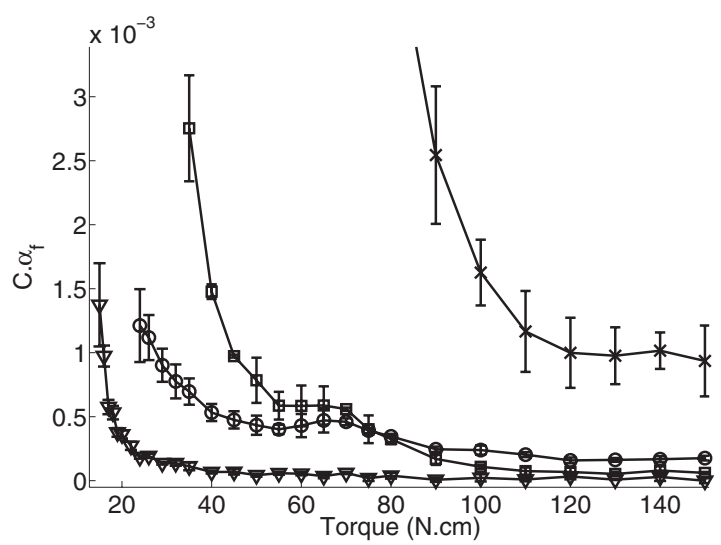

(b)

FIG. 6. (a) Nonlinear elastic parameter $\mathrm{C} \alpha$ as a function of torque for mode nos. $11(\nabla), 20(\square), 21(\bigcirc)$, and $22(\times)$, where $C$ is a constant. Mode No. 11 is present in the spectrum over the entire torque range, while modes 20 , 21 , and 22 appear at torque $35 \mathrm{~N} \mathrm{~cm}, 24 \mathrm{~N} \mathrm{~cm}$, and $35 \mathrm{~N} \mathrm{~cm}$, respectively. (b) Zoom of (a) on modes 11, 20, and 21.

appear progressively in the spectrum when increasing torque and below these torque values, the signal to noise ratio is too weak to perform a reliable measurement. These three modes, appearing during tightening, are considered as new events in the spectrum. In Figs. 6 and 7, we see that parameters $\alpha$ of mode 22 are much higher than others at low torque.

Figure 8 compares linear and nonlinear elastic parameters for the mode no. 11. It appears that nonlinear elastic parameter is sensitive at the beginning of the torque range (from 15 to $40 \mathrm{~N} \mathrm{~cm}$ ) while linear elastic parameter is sensitive from 15 to $80 \mathrm{~N} \mathrm{~cm}$. However, when the nonlinear parameter is sensitive, it is more sensitive than linear one. We also note that the weak error bars in Figs. 6-8 indicate that the measurement is consistent and that our system is only solicited in the elastic domain; the highest torque used $(150 \mathrm{~N} \mathrm{~cm})$ does not induce plastic deformation at the interface.

Figure 9 displays normalized values of linear and nonlinear elastic parameters for modes $11,20,21$, and 22. When sensitive, the nonlinear parameter of each mode is more sensitive than its linear counterpart. Therefore, the addition of modes implies that the nonlinear method is more sensitive than the linear frequency change. An equivalent comparison can be made between linear and nonlinear dissipative param- 


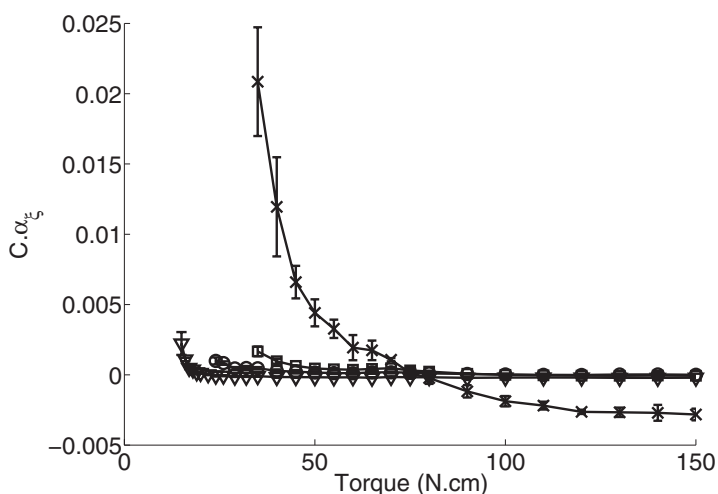

(a)

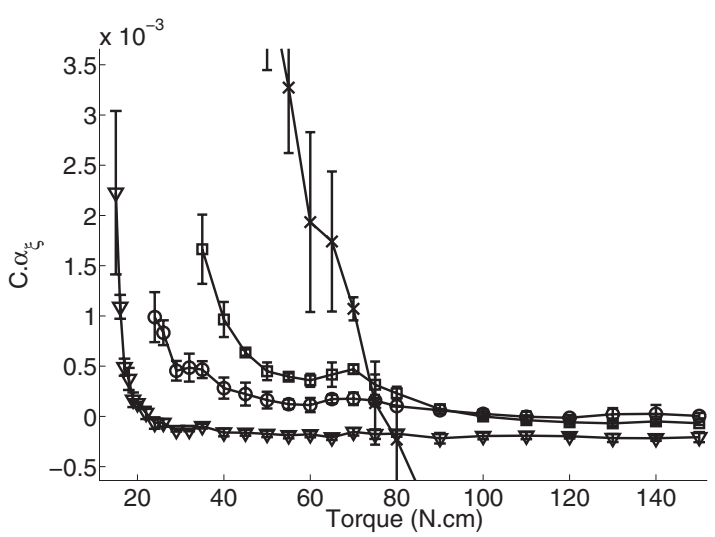

(b)

FIG. 7. (a) Nonlinear dissipative parameter $\mathrm{C} \alpha_{\xi}$ as a function of torque for mode nos. $11(\nabla), 20(\square), 21(\bigcirc)$, and $22(\times)$, where $C$ is a constant. Mode No. 11 is present in the spectrum over the entire torque range, while modes 20, 21, and 22 appear at torque $35 \mathrm{~N} \mathrm{~cm}, 24 \mathrm{~N} \mathrm{~cm}$, and $35 \mathrm{~N} \mathrm{~cm}$, respectively. (b) Zoom of (a) on modes 11, 20, and 21.

eters. The behavior is highly similar, even if modal damping ratio (linear parameter) is more artifacted by the presence of adjacent modes.

Nonlinear parameters provide different information to the system, complementary to linear ones. This point will be developed more in-depth below.

A variation in nonlinear parameters is observed for most modes having a nodal line in the region of the screw, corresponding to a maximum strain. This maximum strain (and

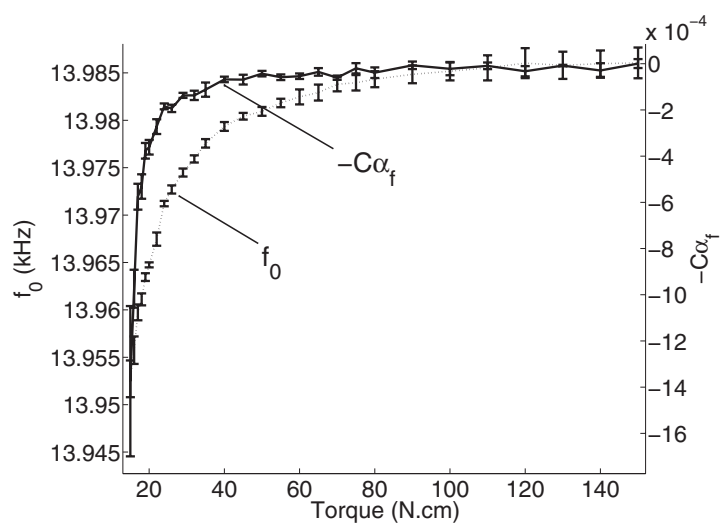

FIG. 8. Mode No. 11. Evolution of linear ( $f_{0}$ in dashed line) and nonlinear ( $-\mathrm{C} \alpha_{f}$ in bold line) elastic parameters vs torque. The opposite value of $\mathrm{C} \alpha_{f}$ is plotted to allow the sensitivity comparison.

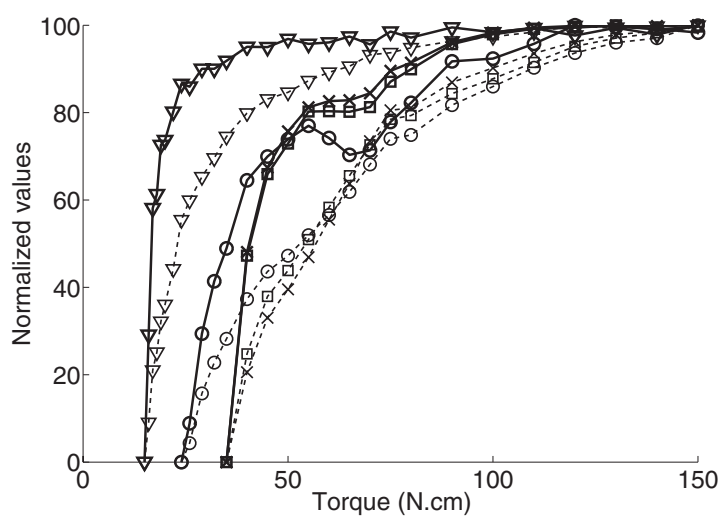

FIG. 9. Normalized values from 0 to 100 for linear ( $f_{0}$ in dashed line) and nonlinear $\left(-\mathrm{C} \alpha_{f}\right.$ in bold line) elastic parameters of mode nos. $11(\nabla), 20$ ( $\square), 21(\bigcirc)$, and $22(\times)$. The opposite value of $\mathrm{C} \alpha_{f}$ is plotted to allow the sensitivity comparison.

stress) at the interface acts as a probing of the threaded interface. Indeed, each bending oscillation will induce a relative micromotion between the screw and the plate, revealing and describing the nonlinear nature of the contact. In contrast, for modes with maximum displacement at the screw (corresponding to a zero strain), the plate and screw move together without (or with weak) relative micromotion, leading to small values $\alpha$, and independent of the torque level. However, some exceptions are noted. Indeed, mode no. 6 or 8 (around $9 \mathrm{kHz}$ ) present a similar nodal line but their parameters $\alpha$ remain independent of torque. We do not fully understand this observation but we speculate that these parameters may be dependent at torques lower than $15 \mathrm{~N} \mathrm{~cm}$. Sensitivity results are summed up in the Table II.

\section{DISCUSSION}

The primary purpose of this study was to show that nonlinear resonance spectroscopy was a useful tool to probe a threaded interface. In an applied aim, we show that this nonlinear method provide a sensitive parameter $\alpha$. A comparison is made between linear and nonlinear parameters. We note they they measure different physical characteristics. The linear measures are of complex moduli and density fluctuation; nonlinearity is a measure of material and interface integrity. It appears that nonlinear parameters are sensitive over a narrower torque range but are more sensitive than linear parameters in this range. Furthermore, by following several modes in the spectrum and by analyzing modes which are not present in the entire torque range, we are able to increase the sensitivity range of the nonlinear approach. This could be implemented in a future as a "nonlinear modal analysis." In terms of basic research this study constitutes one of the first combining nonlinear acoustic methods with threaded interface. Other nonlinear methods (including frequency mixing and slow dynamics experiments) may be tested in the future as well. Both academic and application ways will be discussed in the following subsections.

\section{A. Physical modeling and nonlinearity origins}

For the lowest torques (Fig. 5), the evolution of the relative frequency shift and damping variation in mode no. 11 
TABLE II. Summary of results obtained for each mode. Torque range of sensitivity for $\alpha_{f}$ and $\alpha_{\xi}$ are displayed, as well as the presence of a nodal line of displacement on the screw (corresponding to a maximum strain).

\begin{tabular}{|c|c|c|c|c|c|}
\hline Number & $\begin{array}{l}\text { Frequency } \\
\quad(\mathrm{Hz})\end{array}$ & $\begin{array}{l}\text { Torque range of existence } \\
\qquad(\mathrm{N} \mathrm{cm})\end{array}$ & $\begin{array}{l}\text { Torque range } \\
\text { of sensitivity } \\
\text { for } \alpha_{f} \\
(\mathrm{~N} \mathrm{~cm})\end{array}$ & $\begin{array}{l}\text { Torque range } \\
\text { of sensitivity } \\
\text { for } \alpha_{\xi} \\
(\mathrm{N} \mathrm{cm})\end{array}$ & $\begin{array}{l}\text { Nodal line } \\
\text { on the bolt }\end{array}$ \\
\hline 1 & 1846 & $15-150$ & Very weak & Very weak & No \\
\hline 2 & 3447 & $15-150$ & Very weak & Very weak & No \\
\hline 3 & 4665 & $15-150$ & Very weak & Very weak & No \\
\hline 4 & 4832 & $15-150$ & Very weak & Very weak & Yes \\
\hline 5 & 8140 & $15-150$ & Very weak & Very weak & No \\
\hline 6 & 8373 & $15-150$ & Very weak & Very weak & Yes \\
\hline 7 & 8567 & $15-150$ & Very weak & Very weak & No \\
\hline 8 & 9369 & $15-150$ & Very weak & Very weak & Yes \\
\hline 9 & 10330 & $15-150$ & Very weak & Very weak & No \\
\hline 10 & 13800 & $15-150$ & Very weak & Very weak & No \\
\hline 11 & 14010 & $15-150$ & $15-40$ & $15-30$ & Yes \\
\hline 12 & 15600 & $15-150$ & $15-40$ & $15-40$ & Yes \\
\hline 13 & 16040 & $15-150$ & Very weak & Very weak & No \\
\hline 14 & 17300 & $15-150$ & Very weak & Very weak & No \\
\hline 15 & 17450 & $15-150$ & $15-40$ & $15-40$ & Yes \\
\hline 16 & Not excited & & & & \\
\hline 17 & 19120 & $15-150$ & Overlapping with 18 & Overlapping with 18 & Not detected \\
\hline 18 & 19380 & $15-150$ & Overlapping with 17 & Overlapping with 17 & No \\
\hline 19 & Not excited & & & & \\
\hline 20 & 20790 & $35-150$ & $35-120$ & $35-120$ & Yes \\
\hline 21 & 21460 & $24-150$ & $24-120$ & $24-120$ & Yes \\
\hline 22 & 23800 & $35-150$ & $35-110$ & $35-120$ & Not detected \\
\hline
\end{tabular}

does not seem to be linear but rather quadratic. Thus, by fitting a second order polynomial on these curves, it appears that a combination of $\delta$ and $\alpha$ (cubic and hysteretic nonlinearities, respectively) is more appropriate, reflecting the coexistence of classical and hysteretic regimes simultaneously. Nevertheless, a coarse linear fit allows to compare a same parameter over the entire torque range.

Furthermore, this study points out a need for a model to characterize the nonlinear behavior of a threaded interaction under acoustic wave excitation, and beyond the PM space formalism presented in part II. The nonlinear behavior of the system comes from the interface between the screw and the plate. Indeed, and similarly to rocks where grains (rigid system) are interconnected with softer bondings, the interface screw/plate can be considered as a soft object between two rigid objects (screw and plate themselves). The nonlinearity level will depend on static forces present at the interface, the roughness of both surfaces, the presence of a liquid, etc.

This model will have to describe (1) the coexistence of classical and hysteretic regimes at lower torques and (2) a decrease in both nonlinear parameters with increasing torque until the linear regime, with a faster decrease for the classical parameter.

As a starting point, asperities at the interface are usually modeled as microspheres in contact, and described by a Hertzian nonlinearity. Indeed, this model can describe the presence of classical regime at low torques. This model allows to describe the contact between two unconsolidated spheres under normal forces, giving a classical nonlinear elasticity. ${ }^{51}$ Then, models derived from the Hertz-Mindlin theory take into account both normal and tangential forces and the possibility of a stick/slip behavior. The latter leads to a hysteretic regime ${ }^{52}$ and could be efficient to describe a threaded interaction at higher torques. From these previous considerations, we speculate that the ratio "interface area without stick/slip behavior" over "interface area with stick/slip behavior" could be higher at low torque, corresponding to the evolution from the classical regime to the hysteretic one.

In Figs. 6, 7, and 9, we observe that $\alpha_{f}$ and $\alpha_{\xi}$ remain constant or slightly increase for increasing torques around 65-70 $\mathrm{N} \mathrm{cm}$, and for three modes (20, 21, and 22). This behavior was not expected but does not seem an artifact as it is present for three different modes. One hypothesis that can explain this plateau is that the increasing prestress at the interface (i.e., increasing torque) could be separated in three different regimes. A first one at low torque where both surfaces are only partially in contact, leading to weak contacts at the interface and high nonlinearity level, a second regime at high torque where nonlinearity is near zero, reflecting the fact that both surfaces are in contact, with all asperities squeezed at the interface, and an intermediate regime at midtorque where both surfaces are in contact with asperities not all squeezed and leading to intermediate nonlinearity levels. Finally, the plateau observed at mid-torque could be explained by the fact that asperities, not yet in contact in the first regime, could produce a second nonlinearity source, by friction and/or clapping, at a scale (micrometer or less) lower than in the first regime. This hypothesis, if verified by future experiments, could be of a potential interest as the linear 
corresponding parameters are not influenced during this plateau (see Fig. 9, $f_{0}$ for modes 20, 21, and 22 increase for increasing torques).

Finally, to model the entire sequence of phenomena described in part II (for example slow dynamics effect, not studied here but evaluated in part III, $(<5 \mathrm{~s}))$, we highlight three models that may be applicable. The first one, termed the "soft-ratchet model,"53 combines a nonlinear fast subsystem of longitudinal resonance with a second slow subsystem of ruptured/cohesive intergrain bonds. The fast subsystem includes a nonlinear stress-strain relation based on the Mie potential (generally used in micromechanics to describe intermolecular potentials ${ }^{54}$ ) to describe intergrain relations in rocks. The slow one includes two activation parameters, corresponding to bond rupture and restorations. The second model $^{55}$ combines the PM space with thermally induced transitions to model conditioning and slow dynamics effects. Finally, the third one uses a Preisach-Arrhenius model, derived from the PM space, and which allows to include dispersion of linear and nonlinear acoustic properties taking account thermal fluctuations of the system. ${ }^{47}$ In future work, we will apply one or more of these models to the system.

\section{B. Multimodal measurement}

This study constitutes one of the rare systematic nonlinear resonance spectroscopy applications in a multimodal context. Therefore, we remark on several points. Each mode have to be isolated from adjacent ones to avoid artifacts in the analysis, especially for dissipative parameters. Hence, modes at relatively low frequency are generally the most suitable, as the mode density is low. Moreover, the system geometry has to be as asymmetric as possible, to avoid several eigenmodes around the same frequency. We also observe that the most suitable configuration to perform a measurement occurs when emittor and detector are placed on a strain node (or a maximum displacement), which favors an energetic mode, while the source of nonlinearity is placed on a displacement node (or a maximum strain), which favors a sensitive mode. Also, when the source of nonlinearity remains unknown, sensitivity or insensitivity of different modes allows one to localize it. ${ }^{39}$

\section{Strain level}

The strain level applied by the acoustic wave to thread remains unknown (nonlinear parameter obtained is not $\alpha$ but $\mathrm{C} \alpha$, with a constant $\mathrm{C}$ ). However, by using piezoelectric characteristics of sensors used in the experiment, we are able to obtain an order of magnitude for strain applied to the system. Indeed, strain applied to the emittor is between $10^{-6}$ and $5 \times 10^{-5}$ for the lowest and highest amplitudes of excitation, respectively, while the strain received by the detector is between $5 \times 10^{-9}$ and $10^{-7}$. This evaluation does not give strain values received by the threaded interface but values of this order are speculated.

\section{Measurement artifacts}

We noted previously that for the highest torques, slopes are slightly negative in Fig. 5(b), leading to negative $\alpha_{\xi}$ values such as: they correspond to a transparency effect. ${ }^{56}$ Moreover, when performing the experiment without the screw in place, the nonlinear dissipative parameter is also slightly negative and with similar values. We do not find any physical reasons for this behavior and infer that it arises from electronic devices, bonding of piezoelectric sensors, and/or geometric nonlinearity.

\section{CONCLUSIONS}

This is the first study presenting results of nonlinear resonance spectroscopy to a threaded interface, in a multimodal way. Nonlinear parameters appear to be a useful tool to characterize this interface, complementary to linear ones. We also show that a multimodal study allows to increase the torque range of sensibility. Beyond the application interest, these measurements revealed some physical information on the interface, which can be mainly linked with friction theories. For better comprehension, other nonlinear methods (including frequency mixing and slow dynamics experiments) may be tested in the future to increase characterization. The study will be carried on in the future by both academic works and medical or industrial applications.

${ }^{1}$ F. R. Rollins, IEEE Trans. Sonics Ultrason. SU18, 46 (1971).

${ }^{2}$ H. J. McFaul, Mater. Eval. 32, 244 (1974).

${ }^{3}$ J. S. Heyman, Exp. Mech. 17, 183 (1977).

${ }^{4}$ J. F. Smith and J. D. Greiner, J. Met. 32, 34 (1980).

${ }^{5}$ S. A. Nassar and A. B. Veeram, J. Pressure Vessel Technol. 128, 427 (2006).

${ }^{6}$ S. Chaki, G. Corneloup, I. Lillamand, and H. Walaszek, Mater. Eval. 64, 629 (2006).

${ }^{7}$ T. Zweschper, A. Dillenz, and G. Busse, Insight 43, 173 (2001).

${ }^{8}$ T. Zweschper, A. Dillenz, and G. Busse, Proc. SPIE 4360, 567 (2001).

${ }^{9}$ M. Morozov, G. Rubinacci, A. Tamburrino, S. Ventre, and F. Villone, in Electromagnetic Nondestructive Evaluation (IX), AIP Conf. Proc. No. 25 (AIP, New York, 2005), pp. 195-202.

${ }^{10}$ S. Paillard, G. Pichenot, M. Lambert, H. Voillaume, and N. Dominguez, in Review of Progress in Quantitative Nondestructive Evaluation, AIP Conf. Proc. No. 894 (AIP, New York, 2007), pp. 265-272.

${ }^{11}$ Y. Le Diraison, P. Y. Joubert, and D. Placko, NDT Int. 42, 133 (2009).

${ }^{12}$ N. Raghu, V. Anandaraj, K. V. Kasiviswanathan, and P. Kalyanasundaram, in Neutron and X-ray Scattering in Materials Science and Biology, AIP Conf. Proc. No. 989 (AIP, New York, 2008), pp. 202-205.

${ }^{13}$ J. R. Tarpani, A. H. Shinohara, V. Swinka Filho, R. R. da Silva, and N. V. Lacerda, Mater. Eval. 66, 1279 (2008).

${ }^{14}$ M. Cacciola, Y. Deng, F. C. Morabito, L. Udpa, S. Udpa, and M. Versaci, Int. J. Appl. Electromagn. Mech. 28, 297 (2008).

${ }^{15}$ P. Y. Joubert and J. Pinassaud, Sens. Actuators, A 129, 126 (2006)

${ }^{16}$ N. Meredith, D. Alleyne, and P. Cawley, Clin. Oral Implants Res. 7, 261 (1996).

${ }^{17}$ B. Dhoedt, D. Lukas, L. Muhlbradt, F. Scholz, W. Schulte, F. Quante, and A. Topkaya, Dtsch. Zahnaerztl. Z. 40, 113 (1985).

${ }^{18}$ A. Zagrai, D. Doyle, and B. Arritt, Proc. SPIE 6935, 93505 (2008).

${ }^{19}$ D. Doyle, A. Zagrai, B. Arritt, and H. Cakan, Proceedings of ASME on Smart Materials, Adaptive Structures and Intelligent Systems, 2009, Vol. 2, pp. 209-218.

${ }^{20}$ I. Solodov, K. Pfleiderer, H. Gerhard, S. Predak, and G. Busse, NDT Int. 39, 176 (2006).

${ }^{21}$ P. A. Johnson, T. J. Shankland, R. J. Oconnell, and J. N. Albright, J. Geophys. Res., [Solid Earth Planets] 92, 3597 (1987).

${ }^{22}$ P. A. Johnson, B. Zinszner, and P. N. J. Rasolofosaon, J. Geophys. Res., [Solid Earth] 101, 11553 (1996).

${ }^{23}$ J. Y. Kim, L. J. Jacobs, J. Qu, and J. W. Littles, J. Acoust. Soc. Am. 120, 1266 (2006). 
${ }^{24}$ K. Van Den Abeele and J. De Visscher, Cem. Concr. Res. 30, 1453 (2000)

${ }^{25}$ J. A. TenCate, Rev. Prog. Quant. Nondestr. Eval. 557, 1229 (2001).

${ }^{26}$ C. Payan, V. Garnier, J. Moysan, and P. A. Johnson, J. Acoust. Soc. Am. 121, EL125 (2007)

${ }^{27}$ V. Bucur and P. N. J. Rasolofosaon, Ultrasonics 36, 813 (1998).

${ }^{28}$ M. Muller, A. Sutin, R. Guyer, M. Talmant, P. Laugier, and P. A. Johnson, J. Acoust. Soc. Am. 118, 3946 (2005).

${ }^{29}$ T. J. Ulrich, P. A. Johnson, M. Muller, D. Mitton, M. Talmant, and P. Laugier, Appl. Phys. Lett. 91, 213901 (2007).

${ }^{30}$ W. L. Morris, O. Buck, and R. V. Inman, J. Appl. Phys. 50, 6737 (1979)

${ }^{31}$ I. Y. Solodov, A. F. Asainov, and S. L. Ko, Ultrasonics 31, 91 (1993).

${ }^{32}$ S. Biwa, S. Hiraiwa, and E. Matsumoto, Ultrasonics 44, e1319 (2006).

${ }^{33}$ K. E. A. Van den Abeele, P. A. Johnson, and A. Sutin, Res. Nondestruct. Eval. 12, 17 (2000).

${ }^{34}$ I. Solodov, J. Wackerl, K. Pfleiderer, and G. Busse, Appl. Phys. Lett. 84 5386 (2004).

${ }^{35}$ V. Zaitsev, V. Gusev, and B. Castagnede, Phys. Rev. Lett. 89, 105502 (2002).

${ }^{36}$ B. Mi, J. E. Michaels, and T. E. Michaels, J. Acoust. Soc. Am. 119, 74 (2006).

${ }^{37}$ G. Renaud, S. Calle, and M. Defontaine, Appl. Phys. Lett. 94, 011905 (2009).

${ }^{38}$ K. E. A. Van den Abeele, J. Carmeliet, J. A. Ten Cate, and P. A. Johnson, Res. Nondestruct. Eval. 12, 31 (2000).

${ }^{39}$ K. Van Den Abeele, J. Acoust. Soc. Am. 122, 73 (2007).

${ }^{40}$ L. D. Landau and E. M. Lifshitz, Theory of Elasticity, Theoretical Physics
Vol. 7, 3rd ed. (Butterworth-Heinemann, Oxford, 1986).

${ }^{41}$ J. A. TenCate, D. Pasqualini, S. Habib, K. Heitmann, D. Higdon, and P. A. Johnson, Phys. Rev. Lett. 93, 065501 (2004).

${ }^{42}$ D. Pasqualini, K. Heitmann, J. A. TenCate, S. Habib, D. Higdon, and P. A. Johnson, J. Geophys. Res. 112, B01204 (2007).

${ }^{43}$ L. K. Zarembo and V. A. Krasil'nikov, Sov. Phys. Usp. 13, 778 (1971).

${ }^{44}$ L. A. Ostrovsky, I. A. Soustova, and A. M. Sutin, Acustica 39, 298 (1978).

${ }^{45}$ J. A. Ten Cate and T. J. Shankland, Geophys. Res. Lett. 23, 3019 (1996).

${ }^{46}$ R. A. Guyer, K. R. McCall, and K. Van Den Abeele, Geophys. Res. Lett. 25, 1585 (1998)

${ }^{47}$ V. Gusev and V. Tournat, Phys. Rev. B 72, 054104 (2005).

${ }^{48}$ R. A. Guyer, K. R. McCall, and G. N. Boitnott, Phys. Rev. Lett. 74, 3491 (1995).

${ }^{49}$ R. A. Guyer and P. A. Johnson, Nonlinear Mesoscopic Elasticity: The Complex Behaviour of Rocks, Soil, Concrete (Wiley-VCH, Weinheim, 2009).

${ }^{50}$ P. Johnson and A. Sutin, J. Acoust. Soc. Am. 117, 124 (2005).

${ }^{51}$ L. Ostrovsky and P. A. Johnson, Riv. Nuovo Cimento 24, 1 (2001).

${ }^{52}$ V. Aleshin and K. Van Den Abeele, J. Mech. Phys. Solids 57, 657 (2009).

${ }^{53}$ O. O. Vakhnenko, V. O. Vakhnenko, and T. J. Shankland, Phys. Rev. B 71, 174103 (2005).

${ }^{54}$ H. Y. Erbil, Surface Chemistry of Solid and Liquid Interfaces (Wiley, New York, 2006).

${ }^{55}$ P. P. Delsanto and M. Scalerandi, Phys. Rev. B 68, 064107 (2003).

${ }^{56}$ V. Gusev and V. Y. Zaitsev, Phys. Lett. A 314, 117 (2003). 